\title{
The Association between Physical Activity and Fitness: The Influence of Muslim and Non-Muslim
}

\section{Erwan Ismail, Mohd Radzani Abd Razak, Tajul Arifin Muhamad, Azlan Ahmad Kamal, Mohd Aras Khamis, Ibrahim Elsalhin Hassan Maizi}

Faculty of Education, The National University of Malaysia, Selangor Darul Ehsan, Malaysia

Email: erwanismail245@gmail.com

How to cite this paper: Ismail, E., Razak, M. R. A., Muhamad, T. A., Kamal, A. H., Khamis, M. A., \& Maizi, I. E. H. (2018). The Association between Physical Activity and Fitness: The Influence of Muslim and Non-Muslim. Creative Education, 9, 2101-2110. https://doi.org/10.4236/ce.2018.914152

Received: August 16, 2018

Accepted: October 23, 2018

Published: October 26, 2018

Copyright ( $\odot 2018$ by authors and Scientific Research Publishing Inc. This work is licensed under the Creative Commons Attribution International License (CC BY 4.0).

http://creativecommons.org/licenses/by/4.0/

\section{c) (i) Open Access}

\begin{abstract}
The aim of this study is to investigate the nature and magnitude of the relationship between self-reported physical activity and fitness and the extent to which the association varies with Muslim and Non-Muslim group. Fitness was assessed by use of sub-maximal bicycle ergometer test to predict maximal aerobic capacity, an assessment of body composition and the measurement of upper and lower body strength. Activity pattern and health status will be assessed by questionnaire. A total of 112 subjects focused on male of the staff, postgraduate, and undergraduate student of Birmingham University undergone fitness testing by bicycle ergometer, body composition and self-reported health questionnaire. The inter-relation of the physical characteristics, self-reported exercise behavior, fitness measures, health risk factors such as smoking and alcohol consumption is discussed. Age has the strongest association with fitness measures. Involvement in strenuous exercise as well as exhausting exercise appears to be related to fitness. Percentage body fat is also associated, inversely, with fitness. The difference between the younger and older participants in \% body fat undoubtedly reflects the much greater time spent in vigorous exercise by the Muslim and Non-Muslim participants. However, the differences in BMI between the Muslim and Non-Muslim, for the Muslim and Non-Muslim cohorts respectively, reflect additional mechanisms, as they are largely driven by differences in height rather than mass. These data emphasize the importance of not relying solely on BMI as a measure of size.
\end{abstract}

\section{Keywords}

Fitness, Physical Activity, Lifestyle, Body Composition, Muslim, Non-Muslim 


\section{Introduction}

Aerobic fitness, which refers to maximal aerobic capacity $\left(\mathrm{VO}_{2 \max }\right)$, is usually, but not always, adjusted for body composition or weight. $\mathrm{VO}_{2 \max }$, can be accurately measured directly by gas exchange assessment during maximal exercise on a bicycle ergometer or a treadmill. However, $\mathrm{VO}_{2 \max }$ can also be estimated using sub-maximal exercise testing and this has proved to be a valid and reliable technique (Åstrand \& Rodhal, 1987). Aerobic fitness $\left(\mathrm{VO}_{2 \max }\right)$ is positively associated with a variety of health outcomes; in particular, high levels of fitness are protective against coronary heart disease (CHD) and cardiovascular disease (CVD) morbidity and mortality, as well as risk factors for these outcomes (Yoshiga \& Higuchi, 2003; Strong, Malina, Cameron, Stephen, Roodney, Bernad, Albert, Aviva, Patricia, James, Thomas, Stewart, \& Francois, 2005). A longitudinal study undertaken by (Lee \& Blair, 2002), in a study of men aged 30 to 83 years, reported that low fitness men, irrespective of the fact that they were lean, had a relatively high risk, both all-cause and CVD mortality over an average 8-year follow-up. Indeed, fitness was a more potent predictor of subsequent health status than fatness. More recently, fitness and mortality were observed to be inversely associated for diabetic men of average aged 49 (Church, Cheng, Earnest, Barlow, Gibbons, Priest, \& Blair, 2004). Again, fitness was a stronger predictor of subsequent mortality than body composition. Adjusting for fitness abolished any association between body mass index and mortality.

Levels of physical activity, whether occupational activity (e.g. patrolling, lifting or carrying loads), home maintenance activity (e.g. housework, yard-work), or as part of leisure pursuits (sports participation, walking, golfing, gardening), are often used as a proxy for physical fitness in epidemiological research. This undoubtedly reflects relative ease of measurement. Physical activity can be measured by self-report as the frequency or the volume of time spent in various types or various intensities (light, moderate, and vigorous). Regular physical activity is associated with numerous health benefits, such as reduced risk for cardiovascular disease, diabetes, obesity, some cancers and musculoskeletal conditions. Further, risk for CHD, CVD, and other condition can be reduced through increases in physical activity. The positive association between physical activity and health is now well established (Blair, LaMonte, \& Nichaman, 2004).

The evidence from studies on aerobic fitness and morbidity (particularly for CHD and CVD) is also consistent (Blair, Cheng, \& Holder, 2001). Many studies have now shown a strong inverse relationship between fitness and morbidity (Kemper, Twisk, Koppes, Van Mechelen, \& Post, 2001). A cross-sectional study (McMurray, Ainsworth, Harell, Griggs, \& Williams, 1998) reported increased aerobic power among 1664 law enforcement trainees had a positive influence on CVD risk factors. They concluded that the roots of this association may be traced to adoles. Thus, the negative consequences of low fitness for CHD and CVD morbidity and risk may begin very early in life (Balducci, Zanuso, Cardelli, Salvi, Mazzitelli, Bazuro, Iacobini, Nicolucci, \& Pugliese, 2012; Fogelholm, 
2010). More recently, (Talbot, Morrell, Metter, \& Fleg, 2002) found that higher cardio-respiratory fitness predicted reduced risk of $\mathrm{CHD}$ in individuals who were less than 65 years old. For older participants ( $>65$ years old), both higher cardio-respiratory fitness and high intensity of exercise were associated with fewer indications of CHD among 689 men from the Baltimore Longitudinal Study of Ageing.

There would seem to be very few data on the relationship between self-reported activity levels and fitness at different religions and no consensus as to whether the strength of the association varies with religion. This research attempts to address these questions using a cross-sectional study:

- What is the nature and size of the association between self-reported physical activity and measure of fitness and strength?

- What are other factors related to fitness and strength?

- How do physical activity levels and fitness change with Muslim and Non-Muslim?

- Does the association between physical activity and fitness vary with Muslim and Non-Muslim?

\section{Methodology}

\subsection{Participants}

The male participants were volunteers from among staffs, and the postgraduate and undergraduate body at the University of Birmingham. The final effective sample comprised 112 men. Because recruitment was opportunistic, a substantial proportion (64\%) of the current sample was recruited from the Malaysian Muslim community resident in Birmingham. For this study, participants had to be over 16 years of age and not suffering from any of the following: existing cardiovascular or respiratory disease as revealed by the School of Sport and Exercise Sciences' general health questionnaire, which was administered at the outset. The local ethics committee approved the study and all participants received an information sheet, providing details of the protocol and provided written informed consent.

\subsection{Design}

This study adopted a cross-sectional correlational design. Participants completed a series of questionnaires, assessing among other things, the extent to which they engaged in exercise at different intensities, and had measurements taken of their fitness levels. Of primary interest was the extent to which fitness levels were associated with self-reported exercise behavior.

\subsection{Questionnaire Assessment}

Participants were administered a questionnaire package developed by (Tuxworth, Nevill, White, \& Jenkins, 1986). Leisure physical activity was measured in a number of domains and the frequency of participants' exertions at different in- 
tensity level assessed. With regard to other moderate intensity exertions, participants were asked about their involvement in activities such as gardening, fishing, and golfing. They were also being required to indicate whether they smoked and, if so, had to state how many cigarettes they smoked: under 10 a day, 10 or more a day but less than 20,20 or more a day but less than 30 , or 30 a day or more. Alcohol consumption within the past 12 months was reported in terms of whether participants drank twice a day or more, almost daily, once or twice a week, on special occasions only, or not at all during the last 12 months. Information about marital status was acquired through having participants choose from six alternatives: single, never married, separated, divorced, widowed, married, or living as married.

\subsection{Anthropometric Assessment}

Mass of participants were measured in kilograms wearing minimal clothing, on digital GEC Avery (Model 824/890) scales, and their height determined, with shoes removed, using a SECA stadiometer (Model 220). Body fat assessment was undertaken using the four-site skinfold method (Durnin \& Rahaman, 1967) Harpenden calipers were used to measure the thickness of skinfolds (in millimetres) at the four-designated sites, namely the midpoint of the upper arm over the biceps and over the triceps muscles as well as subscapular and suprailliac sites. The four-skinfold thicknesses were summed and converted, using the formula of (Durnin \& Womersley, 1974) to estimate the percentage body fat. Body mass index (BMI) was calculated from the ratio of mass $(\mathrm{kg})$ to height $(\mathrm{m})^{2}$.

\subsection{Exercise Test and $\mathrm{VO}_{2 \max }$ Determination}

Upper body strength was assessed by having the participant perform a maximum handgrip test, using a Takei Hand-grip Dynamometer. Maximal isometric strength of the knee extensors was determined using a TORNVAL chair. With arms folded across the chest subject performed three maximal efforts attempting to extend the knee against the restraining limb attachment. Each trial was separated by a 60 seconds rest period. The highest force recorded in the three trials was taken as maximum voluntary strength.

Maximum oxygen uptake $\left(\mathrm{VO}_{2 \max }\right)$ was estimated from submaximal cycle exercise, using a Lode Excalibur Sport cycle ergometer. For the handgrip test, participants were instructed to grip as hard as they could on the bar of the dynamometer. They used their dominant hand and were tested while standing. They were also allowed to engage in vocal self-encouragement. The highest score from three trials, each separated by a 30-second recovery period, was adopted as the measure of upper body strength measure. The lower body strength was determined using the leg extensor chair (TORNVAL chair) measuring maximum torque achieved by large muscles at the quadriceps and the hamstrings on the dominant leg. The best recording of the three maximum lifts of the legs, each separated by a 60 -second recovery period, was adopted as the measure of the 
lower body strength.

\subsection{Data Analysis}

Analysis was largely by correlation and regression. The following served as outcome variables: $\mathrm{VO}_{2 \max }$, grip strength, leg strength, and percentage body fat. After bivariate correlational analyses, significant predictors of outcome were then tested in multiple regression models. In all cases, a stepwise approach was used. Binary variables were analyzed by $\chi^{2}$. Differences between older and younger participants were tested using t-tests with continuous variables and $x^{2}$ with binary variable. Finally, separate regression models were tested for the younger and older cohorts.

\section{Results}

The comparisons between these participants and the rest of the sample are summarized in Table 1.

Analysis revealed that these participants engaged in the far less exercise, particularly vigorous exercise than their non-Muslim counterparts. Although groups did not differ in terms of leg strength, the Malaysian Muslim participants registered lower leg strength and lower $\mathrm{VO}_{2 \max }$ values, whether corrected with mass or absolute $\mathrm{VO}_{2 \max }$.

The groups did not differ in terms of Body Mass Index (BMI), but the Muslim participants were shorter, lighter, and had significantly higher percentage of body fat values. Although the groups did not vary in self-reported general health, with both groups reporting very good health, they did differ in terms of health behaviors.

The Muslim group were far less likely to drink alcohol, but much more likely to be current smokers. They were also more likely to be married, but not more likely to be in paid employment. Finally, they were, on average, older than the non-Muslim participants.

Given that religion or ethnicity and age cohort were confounded, age differences were reexamined considering Muslim and Non-Muslim. This was achieved using analyzed of covariance, with age cohort as the variate and religion as the covariate. The outcomes of these analyses are presented in Table 2. As can be seen, age cohort differences in vigorous and total exercise, $\mathrm{VO}_{2 \max }$, and leg strength remained even when religion was considered.

\section{Discussion and Conclusion}

Considered as a whole, the largely student sample in this study spent more (72\%) of their exercising time engaged in moderate exercise, such as walking, sport play, and golfing, than vigorous exercise, such as running and competitive sports. Previously, (American College of Sports Medicine, 1995; Weyer, Linkeschowa, Heise, Giesen, \& Spraul, 1998) recommended at least 20 minutes of vigorous exercise undertaken at least 3 times per week. Thus, their weekly 
Table 1. Summary statistics of the physical characteristics, self-reported exercise behaviors, and fitness measures for the Muslim (tee-total) and Non-Muslim (non-teetotal) participants.

\begin{tabular}{|c|c|c|c|c|c|c|c|c|}
\hline \multirow{2}{*}{ Variable } & \multicolumn{3}{|c|}{ Muslim } & \multicolumn{3}{|c|}{ Non-Muslim } & \multirow[b]{2}{*}{$t$} & \multirow[b]{2}{*}{$p$} \\
\hline & $N$ & Mean & $S D$ & $N$ & Mean & $S D$ & & \\
\hline Age (years) & 72 & 31.86 & 7.02 & 40 & 26.68 & 10.09 & 3.19 & 0.002 \\
\hline Height (m) & 72 & 1.67 & 0.06 & 40 & 1.77 & 0.08 & 7.11 & 0.000 \\
\hline Mass (kg) & 72 & 69.36 & 13.30 & 40 & 75.86 & 10.89 & 2.65 & 0.009 \\
\hline BMI $\left(\mathrm{kg} \cdot \mathrm{m}^{-2}\right)$ & 72 & 24.74 & 4.27 & 40 & 24.33 & 3.21 & 0.53 & 0.60 \\
\hline $\begin{array}{c}\text { Moderate Exercise Time } \\
\text { (hrs/week) }\end{array}$ & 68 & 6.65 & 1.81 & 40 & 7.14 & 1.97 & 1.30 & 0.20 \\
\hline $\begin{array}{c}\text { Strenuous Exercise Time } \\
\text { (hrs/week) }\end{array}$ & 70 & 1.06 & 1.26 & 40 & 2.65 & 1.57 & 5.81 & 0.000 \\
\hline $\begin{array}{c}\text { Competitive Exercise Time } \\
\text { (hrs/week) }\end{array}$ & 70 & 0.64 & 1.05 & 40 & 1.84 & 1.45 & 5.01 & 0.000 \\
\hline $\begin{array}{c}\text { Vigorous Exercise Time } \\
\text { (hrs/week) }\end{array}$ & 72 & 1.65 & 1.81 & 40 & 4.49 & 2.42 & 6.63 & 0.000 \\
\hline $\begin{array}{l}\text { Total Exercise Time } \\
\text { (hrs/week) }\end{array}$ & 68 & 8.26 & 2.99 & 40 & 11.63 & 3.05 & 5.61 & 0.000 \\
\hline $\mathrm{VO}_{2 \max }\left(\mathrm{ml} \cdot \mathrm{kg}^{-1} \cdot \mathrm{min}^{-1}\right)$ & 68 & 41.1 & 11.4 & 39 & 55.3 & 14.9 & 5.54 & 0.000 \\
\hline $\mathrm{VO}_{2 \max }\left(1 \cdot \min ^{-1}\right)$ & 68 & 2.78 & 6.36 & 39 & 4.13 & 1.04 & 0.008 & 0.000 \\
\hline$\%$ body fat & 72 & 20.96 & 5.76 & 40 & 17.80 & 6.47 & 2.66 & 0.009 \\
\hline Leg strength $(\mathrm{N})$ & 66 & 369 & 105 & 40 & 544 & 139 & 7.34 & 0.000 \\
\hline \multirow[t]{2}{*}{ Grip strength $(\mathrm{N})$} & 72 & 442 & 70 & 40 & 453 & 86 & 7.75 & 0.46 \\
\hline & \multicolumn{2}{|c|}{ Muslim } & \multicolumn{2}{|c|}{ Non-Muslim } & $\chi^{2}$ & $\mathrm{p}$ & & \\
\hline Smokers (\% current smokers) & & 42 & 13 & & $10.49^{1}$ & 0.001 & & \\
\hline $\begin{array}{l}\text { Alcohol Consumption } \\
\text { (\% not tee-total) }\end{array}$ & & 1 & 89 & & $85.71^{1}$ & 0.000 & & \\
\hline $\begin{array}{l}\text { General Health } \\
\text { (\% good/very good) }\end{array}$ & & 82 & 88 & & $0.59^{1}$ & 0.44 & & \\
\hline Marital Status (\% single) & & 39 & 88 & & $24.69^{1}$ & 0.000 & & \\
\hline $\begin{array}{c}\text { Employment } \\
\text { (\% in paid employment) }\end{array}$ & & 43 & 43 & & $0.003^{1}$ & 0.96 & & \\
\hline
\end{tabular}

${ }^{1}$ For binary variables, the percentage showing the characteristic is presented.

energy expenditures were well above $1000 \mathrm{kcal}$ per week. With regard to moderate exercise, our participants were expending a mean estimated $1958 \mathrm{kcal}$ per week and, in total, were expending an estimated $3665 \mathrm{kcal}$ per week. Clearly, they were, on average, meeting current exercise recommendations for weight loss and health.

Further, the age effects discussed below could be helping deflate the overall estimate for the sample of time spent in vigorous exercise in the current study; it is clear that younger participants in the study spent more than twice as much time engaged in vigorous exercise than the older participants. Whereas the younger cohort was spending the estimated $4447 \mathrm{kcal}$ per week engaged in exercise, for the older cohort, the estimate was $2930 \mathrm{kcal}$ per week. It should be noted, however, 
Table 2. Differences between old and young cohorts considering Muslim and Non-Muslim affiliation.

\begin{tabular}{cccc}
\hline Variable & $F$ & $D f$ & $P$ \\
\hline Age & 260.68 & $1 / 109$ & $<0.001$ \\
Height & 1.27 & $1 / 109$ & 0.26 \\
Mass & 6.48 & $1 / 109$ & 0.01 \\
$\mathrm{VO}_{2 \max }$ corrected with mass & 41.23 & $1 / 104$ & $<0.001$ \\
$\mathrm{VO}_{2 \text { max }}$ absolute & 25.64 & $1 / 104$ & $<0.001$ \\
\% body fat & 29.22 & $1 / 109$ & $<0.001$ \\
BMI & 11.83 & $1 / 109$ & 0.001 \\
Grip strength & 5.76 & $1 / 109$ & 0.018 \\
Leg strength & 12.42 & $1 / 103$ & 0.001 \\
Strenuous exercise & 7.92 & $1 / 107$ & 0.006 \\
Exhaustive exercise & 37.09 & $1 / 107$ & $<0.001$ \\
Time spent in moderate exercise & 1.20 & $1 / 105$ & 0.28 \\
Time spent in vigorous exercise & 21.32 & $1 / 109$ & $<0.001$ \\
Total time spent in exercising & 13.13 & $1 / 105$ & $<0.001$ \\
\hline
\end{tabular}

that the older members of the present sample were still exercising at well above the recommended minimum levels.

These sorts of difference in physical activity levels are also apparent in the present study. For the non-Muslim members of the sample, the average estimated energy expenditure in physical activity and exercise was $5171 \mathrm{kcal}$ per week, whereas for the Muslim participants, it was 2877 kcal per week. Again, however, this latter figure is still above the recommended exertion levels. While there is consistent evidence that leisure exercise is protective of health and is associated with reductions in premature death, particularly from coronary heart (Lee \& Paffenbarger Jr., 2000; Carnethon, Sternfeld, Schreiner, Jacobs, Lewis, \& Liu, 2009), there is still debate about the necessary intensity required to gain such benefits. It remains possible that reductions in risk for coronary heart disease require reasonably vigorous exercise. This is what is reported from a recent analysis of the Caerphilly study data (Yu, Yarnell, Sweetnam, \& Murray, 2003). The present participants were, on average, spending $1707 \mathrm{kcal}$ per week on vigorous exercise, which clearly falls within the range apparently required to gain this benefit.

Muslim participants in the present study had lower estimated $\mathrm{VO}_{2 \max }$ values of $41 \mathrm{ml} \cdot \mathrm{kg}^{-1} \cdot \mathrm{min}^{-1}$ than the rest of the cohort, who had an average value of 55 $\mathrm{ml} \cdot \mathrm{kg}^{-1} \cdot \mathrm{min}^{-1}$, indicative of good levels of fitness. (Singh, Singh, \& Sirisinghe, 1989) reported that $\mathrm{VO}_{2 \max }$ values for Malaysian healthy men age 13 until 59 years varied with age in systematic manner. Based on the formula developed to determine $\mathrm{VO}_{2 \max }$ value; $\mathrm{VO}_{2 \max }$ value $\left(\mathrm{ml} \cdot \mathrm{kg}^{-1} \cdot \mathrm{min}^{-1}\right)=67.7-0.77$ (age), partic- 
ipants with an age mean of 31.86 years would register a $\mathrm{VO}_{2 \max }$ value of 43.2 $\mathrm{ml} \cdot \mathrm{kg}^{-1} \cdot \mathrm{min}^{-1}$ which is very much similar to this study's $\mathrm{VO}_{2 \max }$ value of 41 $\mathrm{ml} \cdot \mathrm{kg}^{-1} \cdot \mathrm{min}^{-1}$ for our sample of Malay Muslims. However, it is likely that the differences in $\mathrm{VO}_{2 \max }$ found in the present study reflected differences in physical activity levels rather than genetic variations. (Bouchard \& Rankinen, 2001) concluded from a review that ethnic variation was little involved as a determinant of physiological adaptations to regular physical activity. The differences among ethnic groups in terms of aerobic power were small, and when other factors were considered, there was little evidence for genuine ethnic differences in maximum aerobic power (Boulay, Ama, \& Bouchard, 1988).

Finally, reported time spent in moderate physical activity at the original, but not the current, assessment appeared to reduce the like hood of a diagnosis of high blood pressure. In addition, those who spent more time in moderate physical activity 23 years earlier were less likely to have at least one of the risk factors for coronary heart disease at current assessment. For the future study, the researcher should do the biggest scope to get the best result with differences gender, carrier, and status.

\section{Acknowledgements}

I would like to thank all the participants for allowing me to access them. I would also like to thank Dr. Mohd Radzani as a supervisor and for their interest and help with this research. Lastly, I dedicate my work to all member and family that support me from beginning.

\section{Conflicts of Interest}

The authors declare no conflicts of interest regarding the publication of this paper.

\section{References}

American College of Sports Medicine (1995). ACSM's Guidelines for Exercise Testing and Prescription (5th Ed.). USA: Williams \& Wilkin.

Åstrand, P., \& Rodhal, K. (1987). Textbook of Work Physiology: Physiological Bases of Exercise (3rd Ed.). New York: McGraw-Hill.

Balducci, S., Zanuso, S., Cardelli, P., Salvi, L., Mazzitelli, G., Bazuro, A., Iacobini, C., Nicolucci, A., \& Pugliese, G. (2012). Cardiovascular Risk Factors Independently of Body Weight Loss in Subjects with Type 2 Diabetes Participating in the Italian Diabetes and Exercise Study (IDES). Diabetes Care, American Diabetes Journal, 35, 1347-1354. https://doi.org/10.2337/dc11-1859

Blair, S. N., Cheng, Y., \& Holder, J. S. (2001). Is Physical Activity or Physical Fitness More Important in Defining Health Benefits? Medicine \& Science in Sports and Exercise, 33, S379-S399. https://doi.org/10.1097/00005768-200106001-00007

Blair, S. N., LaMonte, M. J., \& Nichaman, M. Z. (2004). The Evolution of Physical Activity Recommendations: How Much Is Enough? American Journal of Clinical Nutrition, 79, 913S-920S. https://doi.org/10.1093/ajcn/79.5.913S

Bouchard, C., \& Rankinen, T., (2001). Individual Differences in Response to Regular 
physical Activity. Medicine \& Science in Sports and Exercise, 33, S446-S443. https://doi.org/10.1097/00005768-200106001-00013

Boulay, M. R., Ama, P. F., \& Bouchard, C. (1988). Racial Variation in Work Capacities and Powers. Canadian Journal of Sport Science, 13, 127-135.

Carnethon, M. R., Sternfeld, B., Schreiner, P. J., Jacobs, D. R., Lewis, C. E., \& Liu, K. (2009). Association of 20-Year Changes in Cardiorespiratory Fitness with Incident Type 2 Diabetes, The Coronary Artery Risk Development in Young Adults (CARDIA) Fitness Study. Diabetes Care, American Diabetes Association, 32, 1284-1288. https://doi.org/10.2337/dc08-1971

Church, T. S., Cheng, Y. J., Earnest, C. P., Barlow, C. E., Gibbons, L. W., Priest, E. L., \& Blair, S. N. (2004). Exercise Capacity and Body Composition as Predictors of Mortality among Men with Diabetes. Diabetes Care, 27, 83-88.

https://doi.org/10.2337/diacare.27.1.83

Durnin, J. V. G. A., \& Rahaman, M. M. (1967). The Assessment of the Amount of Fat in the Human Body from the Measurement of Skinfold Thickness. British Journal of Nutrition, 21, 681-688. https://doi.org/10.1079/BJN19670070

Durnin, J. V., \& Womersley, J. (1974). Body Fat Assessed from Total Body Density and Its Estimation from Skinfold Thickness: Measurements on $481 \mathrm{Men}$ and Women Aged from 16 to 72 Years. British Journal of Nutrition, 32, 77-97.

https://doi.org/10.1079/BJN19740060

Fogelholm, M. (2010). Physical Activity, Fitness and Fatness: Relations to Mortality, Morbidity and Disease Risk Factors. A Systematic Review. International Association for the Study of Obesity, 11, 202-221. https://doi.org/10.1111/j.1467-789X.2009.00653.x

Kemper, H. C., Twisk, J. W., Koppes, L. L., Van Mechelen, W., \& Post, G. B. (2001). A 15-Year Physical Activity Pattern Is Positively Related to Aerobic Fitness in Young Males and Females (13 - 27 Years). European Journal of Applied Physiology, 84, 395-402. https://doi.org/10.1007/s004210100392

Lee, C. D., \& Blair, S. N. (2002). Cardio-Respiratory Fitness and Smoking-Related and Total Cancer Mortality in Men. Medicine \& Science in Sports \& Exercise, 34, 735-739. https://doi.org/10.1097/00005768-200205000-00001

Lee, I.-M., \& Paffenbarger Jr., R. S. (2000). Association of Light, Moderate, and Vigorous Intensity Physical Activity with Longevity. The Harvard Alumni Health Study. American Journal of Epidemiology, 151, 293-299.

https://doi.org/10.1093/oxfordjournals.aje.a010205

McMurray, R. G., Ainsworth, B. E., Harell, R. S., Griggs, T. R., \& Williams, O. D. (1998). Is Physical Activity or Aerobic Power More Influential on Reducing Cardiovascular Disease Risk Factors? Medicine \& Science in Sport and Exercise, 30, 1521-1529. https://doi.org/10.1097/00005768-199810000-00009

Singh, R., Singh, H. J., \& Sirisinghe, R. G. (1989). Cardio-Pulmonary Fitness in a Sample of Malaysia Population. Japan Journal of Physiology, 39, 475-485.

Strong, W. B., Malina, R. M., Cameron, J. R., Stephen, R., Roodney, K., Gutin, B., Albert, C., Aviva, M., Patricia, A., James, M., Thomas, R., Stewart, T., \& Francois, T. (2005). Evidence Based Physical Activity for School-Age Youth. The Journal of Pediatrics, 146, 732-737. https://doi.org/10.1016/j.jpeds.2005.01.055

Talbot, L. A., Morrell, Metter, E. J., \& Fleg, J. L. (2002). Comparison of Cardio-Respiratory Fitness versus Leisure Time Physical Activity as Predictors of Coronary Events in Men Aged < or 65 Years and >65 Years. American Journal of Cardiology, 89, 1187-1192. https://doi.org/10.1016/S0002-9149(02)02302-0

Tuxworth, W., Nevill, A. M., White, C., \& Jenkins, C. (1986). Health, Fitness, Physical 
Activity, and Morbidity of Middle-Aged Male Factory Workers. British Journal of Industrial Medicine, 43, 733-753.

Weyer, C., Linkeschowa, R., Heise, T., Giesen, H. T., \& Spraul, M. (1998). Implication of the Traditional and the New ACSM Physical Activity Recommendation on Weight Reduction in Dietary Treated Obese Subjects. International Journal of Obesity Related Metabolic Disorder, 22, 1071-1078. https://doi.org/10.1038/sj.ijo.0800728

Yoshiga, C. C., \& Higuchi, M. (2003). Oxygen Uptake and Ventilation during Rowing and Running in Females and Males. Scandinavian Journal of Medicine \& Science in Sports, 13, 359-363. https://doi.org/10.1046/j.1600-0838.2003.00324.x

Yu, Y. S., Yarnell, J. W. G., Sweetnam, P. M., \& Murray, L. (2003). What Level of Physical Activity Protects against Premature Cardiovascular Death? The Caerphilly Study. Heart (British Cardiac Society), 89, 502-506. https://doi.org/10.1136/heart.89.5.502 